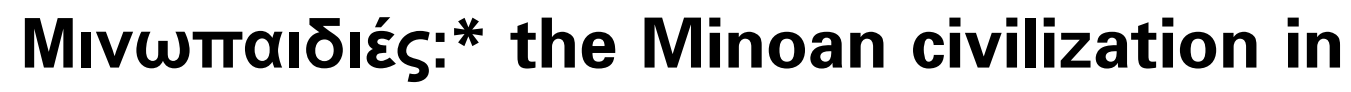 Greek primary education
}

\section{Anna Simandiraki}

\begin{abstract}
This paper discusses the representation and teaching of the Minoan civilization (Crete, c. 3000-1400 BC) in Greek primary education. Unlike Classical civilization, the Minoan civilization is a period less charged with nationalistic connotations. As primary education seems freer to experiment with the transmission of cultural knowledge than universities, I examine how this part of the past is taught. After an account of the current 'Minoan' educational experience (within and outside the curriculum), an analysis of primary school historical/archaeological education and the cognitive processes that have led to it is attempted. A theoretical model of the interplay of archaeology and the public is proposed, so as to place this pedagogy in a wider framework. Finally, issues of narrative, corporeality and cultural symbols are raised.
\end{abstract}

\section{Keywords}

Minoan archaeology; nationalism; cultural identity; history education; popular archaeology.

\section{Introduction}

Greece is an area rich in cultural heritage and turbulent history, so the latter forms an integral part of Greek education, taught at almost all levels. While some of its aspects are given more attention (e.g. Classical Greece with its battles and wars, the War of Independence 1821-30, etc.), the overall curriculum caters for the entirety of what is perceived as the historical continuum of the Greek world. Certain ages lend themselves to certain historical periods more than others (Hamilakis 2003), hence the Minoan civilization (Crete, c. 3000-1400 BC) is covered by third grade history; the Minoans are not the only part of prehistory being taught - they are thematically positioned after the Stone Age and before the Mycenaean civilization. This phase of history has mostly been associated with mythology, which presumably constitutes a gentle way of acquainting schoolchildren with ancient Greek beliefs, historical narrative and the notions of time and 
space. This examination is not meant to be exhaustive, but highlights particular issues arising from particular socio-political contingencies. By proposing a framework of archaeological, educational and socio-political interaction, this can be taken as an initial response to Hamilakis's invitation for alternative ways to analyse such pedagogic materials (2002a: 4, 15ff.).

\section{The school experience}

\section{Main curriculum for Minoan studies}

Until recently, the history textbook for third grade pupils (age 8) was the only source of

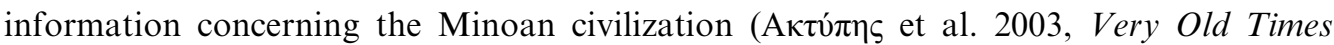
henceforth). I will not expand greatly here (Hamilakis (2003: 44-9) has also already commented on this book), but will, however, examine its Minoan section more closely. This book is used throughout Greece and its departure from its almost monotonously Classicist predecessors is refreshing. It is subdivided into units which, despite employing mythology to a great extent, follow an evolutionist chronological order. 'Minoan Crete', therefore, occupies Section B (chapters 9-19), just after Section A: 'Humanity Progresses' (chapters 1-8) and before Section C: 'The Gold of Mycenae' (chapters 20-7), Section D: 'Greek Religion' (chapters 28-38), Section E: 'Heroic Feats' (chapters 39-42), Section $\Sigma \tau$ : 'Iliad and Odyssey' (chapters 43-5), Section Z: 'Mythic Heroes' (chapters 46-53) and the Appendix, pertaining to a museum visit.

Although this examination is not intended as a book review, some worthwhile points about the textbook and indeed the Minoan section emerge. These concern a) the 'mechanics' (way of teaching) and b) the contents of the book. First, in terms of 'mechanics', the book tries to engage pupils as much as possible: filled with visual material and lots of exercises (e.g. gap filling, crafts), it provides adequate but interspersed information, so that knowledge is digested through continuous engagement. Second, in terms of content, the most prominent tendency is to fuse mythical, historical and archaeological components to provide an accessible representation of a period whose material remains are subject to multivocal interpretation at a specialist level. Here are the chapters:

9 'King Minos'

10 'The harmony of colours'

11 'Life in King Minos's times'

12 'Worship and religious festivals'

13 'Cretans at the forefront of seafaring and trade'

14 'Glorious vases and ornaments'

15 'This is writing too'

16 'Daedalos and Ikaros'

17 'A monster in the dark'

18 'The famous palaces are destroyed'

19 'Excavations at Knossos' 
Another point on content is the continuous attempt for pupils to make connections and comparisons between the Minoan civilization and everyday life (e.g. p. 39, question 2). In this case, the pupil is guided towards incorporating this part of the past into his/her immediate temporal and spatial environment, thereby engaging in a mutual relationship with it: on the one hand, the pupil is an active cultural producer, s/he restructures the past; on the other hand, the past provides the pupil with a connection and potential knowledge.

\section{The Melina Educational Programmes}

As, until recently, Very Old Times was the main/only source of information about the Minoan civilization in structured pre-university education, teachers would sometimes take the initiative, producing hand-outs, activities and exercises of their own (e.g. $\Delta \rho \alpha \kappa \alpha ́ \kappa \eta$ 1997, 1999). The 'Melina Educational Programmes' were designed in 1994 and introduced

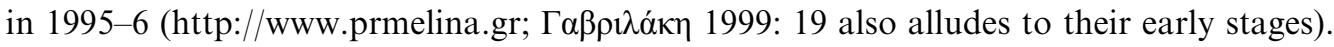
These programmes were developed in collaboration with both Greek (Greek Pedagogic Institute, Teachers' Association, universities, etc.) and international educational institutions, e.g. the European Council and Binghamton University, New York. They aim to enhance history and culture in the elementary schoolchildren's worldview mainly by utilizing interaction and multidisciplinary education. For example, a museum visit would not only include static observation of the artefacts, it would also involve the pupils by way of re-enactment (a play), visual expression (drawing), deductive skills (mathematical calculations, to find, e.g., how many pithoi (storage jars) of produce the Minoan trader has sold).

The Programmes' timeline was intentionally arranged into successive phases: they began as a pilot project at a handful of schools throughout Greece, with the intention of spreading to all primary schools, secondary education and beyond. Teachers attended several seminars, in order to facilitate this new (for Greek education) instructional system, but also to train others in the subsequent phases of the Programmes.

The Ministries of Culture and Education forged links between the pilot schools and the local Archaeological Ephorates to produce materials accommodating this educational endeavour and at the same time building on the existing educational resources. Consequently, additional materials were created, mainly by archaeologists collaborating with or working at the Ephorates. The materials usually correspond with particular sites pupils visit (see below) and are available throughout Greece, but this might not be practical depending on geography (e.g. a child from Thessaloniki is unlikely to visit Knossos, just as a child from Heraklion is unlikely to visit Vergina on a school trip).

The new 'Minoan' material reveals the practice of entrusting archaeologists with teaching facts through their textbooks, but also the expressed desire to use those additional materials to expand on issues which the school textbook simply touches upon. Almost every unit includes a teacher's and a pupil's textbook, which provide adequate and appropriate information. The teachers' textbooks are detailed, concise and far from patronizing. The Minoan civilization section of third grade history can even take an entire month when taught in Cretan schools nowadays (A. Papadakis, personal communication), particularly when used in conjunction with additional materials. The Melina Programmes are a different approach to the teaching of archaeology. Their textbooks are written by 
active field archaeologists who are up-to-date with recent debates and data. Additionally, the materials are of great help to teachers, very informative and potentially flexible.

The Programmes' experiential side is commented on below, but it is worth noting here that they work on a 'before, during, after' basis. Preparation is carried out in the classroom, similarly to using Very Old Times. Then a site visit is arranged, during which the teacher might be joined by an archaeologist/guide. Children are encouraged to take learning into their hands by interacting with space and time (e.g. enact the Bull Leaping

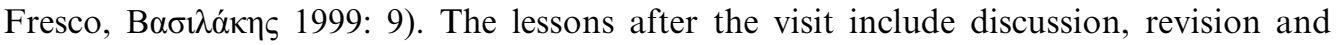
Minoan-inspired activities.

\section{The extra-curricular experience}

Apart from the 'structured' experience of school instruction, there are extra-curricular learning opportunities concerning the Minoan civilization. Here are a few examples:

- museum visits with family/friends: although some families visit the museum more often than others, the majority combines this activity with the (summer) holidays.

- excavation open days: some archaeologists organize excavation open days for the public, but with fewer open days specifically themed for children. An open day at Petras Siteias (mid-1990s) is one example of the latter (M. Tsipopoulou, personal communication).

- books: there are two kinds of non-school books which are relevant here, educational and novels. Educational books mostly fuse fact and myth in much the same way the schoolbooks do (see below for criticism). In fact, the structure of Very Old Times

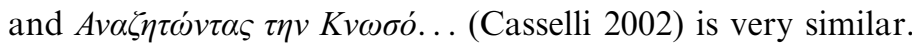

The novels use archaeological imagery and frequently dramatize myths, but at least they are explicitly fictional and do not advocate mythology as historicity. An example is Kazantzakis's In the Palaces of Knossos (2001), where the fusion is almost seamless (cf. descriptions of scenes based on real life artefacts, like the harvester parade scene of p. 60, directly based on and indeed describing the so-called Harvester Vase).

- the press: newspapers frequently publish articles of popularized Minoan themes. However, it would be fair to assume that schoolchildren would mainly read certain

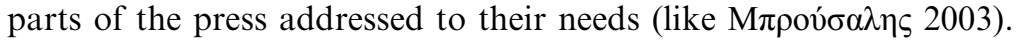

- films: the Disney film The Moon Spinners (based on Mary Stewart's 1962 book) is an example of Minoan popularization, as it includes a fictitious Minoan-style festival in modern Crete.

- computer games: computer games using Minoan imagery and stereotypes do exist, e.g. 'Age of Empires', 'Minotaur, the Labyrinths of Crete', 'Legacy'. The use of stereotypes is understandable here: the creators have usually not studied the Minoan civilization beyond the odd textbook and so build on their limited (mainly visual) knowledge.

- cultural activities, e.g. an enacted ritual by the Lykeio ton Ellinidon: this nationwide folklore society aims to promote traditional activities; as such, it participates in the 
two national annual parades, owns a wardrobe of local costume, organizes lectures, dance and music lessons and, occasionally, puts on theatrical plays. The Lykeio ton Ellinidon of Heraklion owns reproductions of Minoan costumes and occasionally

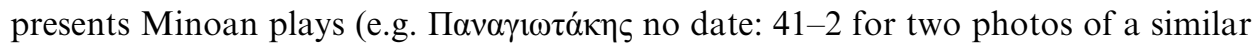
play).

- carnival: it is not uncommon to see carnival floats and groups 'commemorating' the Minoan past, especially in Crete (Plates 1a and 1b).

- athletic events: a very prominent example of this is the Athens Olympic Games this year (2004). Knossos features as a Greek symbol, Heraklion is an 'Olympic city' (a contradiction in etymological terms), collectors' pins explicitly depict Minoan imagery, e.g. the Prince of Lilies and the Ladies in Blue, while a 'Minoan ship' was built and launched in Chania as part of the 'Cultural Olympiad' (interestingly enough, no archaeologist was on the organizing committee for this project (e.g.

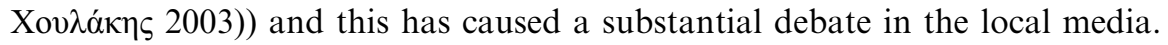

Although these resources are available to children throughout Greece, Crete has a particular advantage, as the Minoan civilization is also potent in everyday life there. Hamilakis and Yalouri (1996: esp. 124-6; Hamilakis 2002a: 3), Farnoux (2003) and others have already shown that there has been a wave of 'Minoanism' (for lack of a better term) mainly since the systematic excavation of Knossos at the beginning of the twentieth century. The Cretan educational experience, while incorporating all other extra-curricular resources, is more intense. Eating 'Minos olive oil', travelling by 'Minoan Ferries', buying 'Prince of Crete' wine from 'Ariadne Supermarkets' on 'Evans Street' (Simandiraki in preparation a) are a few examples of how one historical period (the Minoan) has woven itself into another (the present).

\section{Paradigm analysis}

\section{Rites of passage}

I shall start with a suggestion of what the relationship between archaeology and the public could look like (Fig. 1). To elaborate, I consider the interplay of archaeology and the public as a dynamic relationship filtered through but not limited to four strata/realms:

Realm 1: factual This is where information originates. It is the realm of the data as they rest forgotten and undiscovered, an incomplete assemblage per se, as only the material dimension remains. Any meanings, feelings, behaviours, interactions, etc., are detached and not preserved, save for their material imprint, which thus partially testifies to an original milieu. The contents of this realm are limited to the particular material culture alone. It can be argued that there may be a Realm 0, which consists of the original processes which accumulated the contents of Realm 1 .

Realm 2: acceptive This is when specialists retrieve the contents of Realm 1, when the Factual Realm is accessed and when, as a result, the archaeological record is created (cf. 
(a)

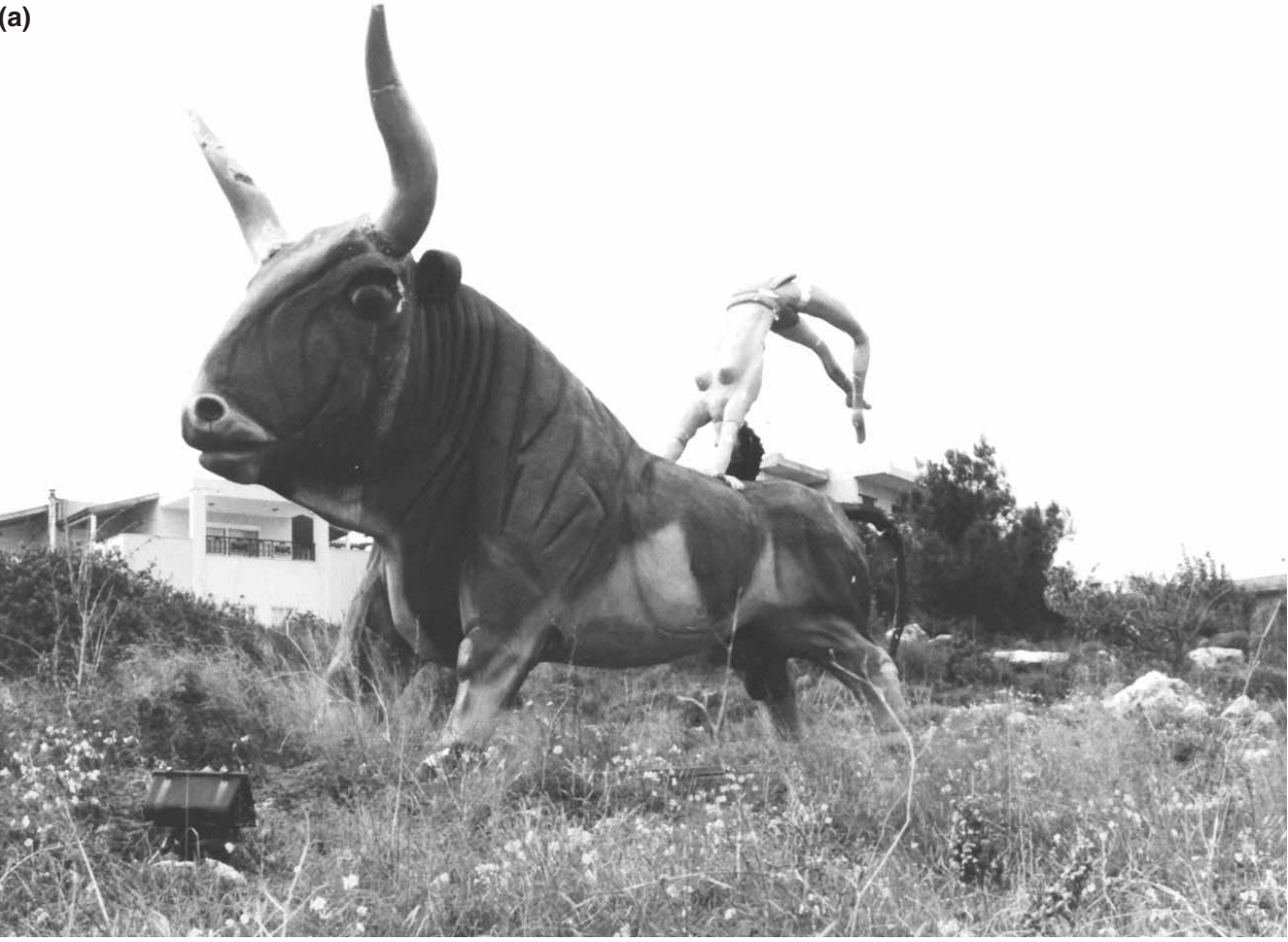

(b)

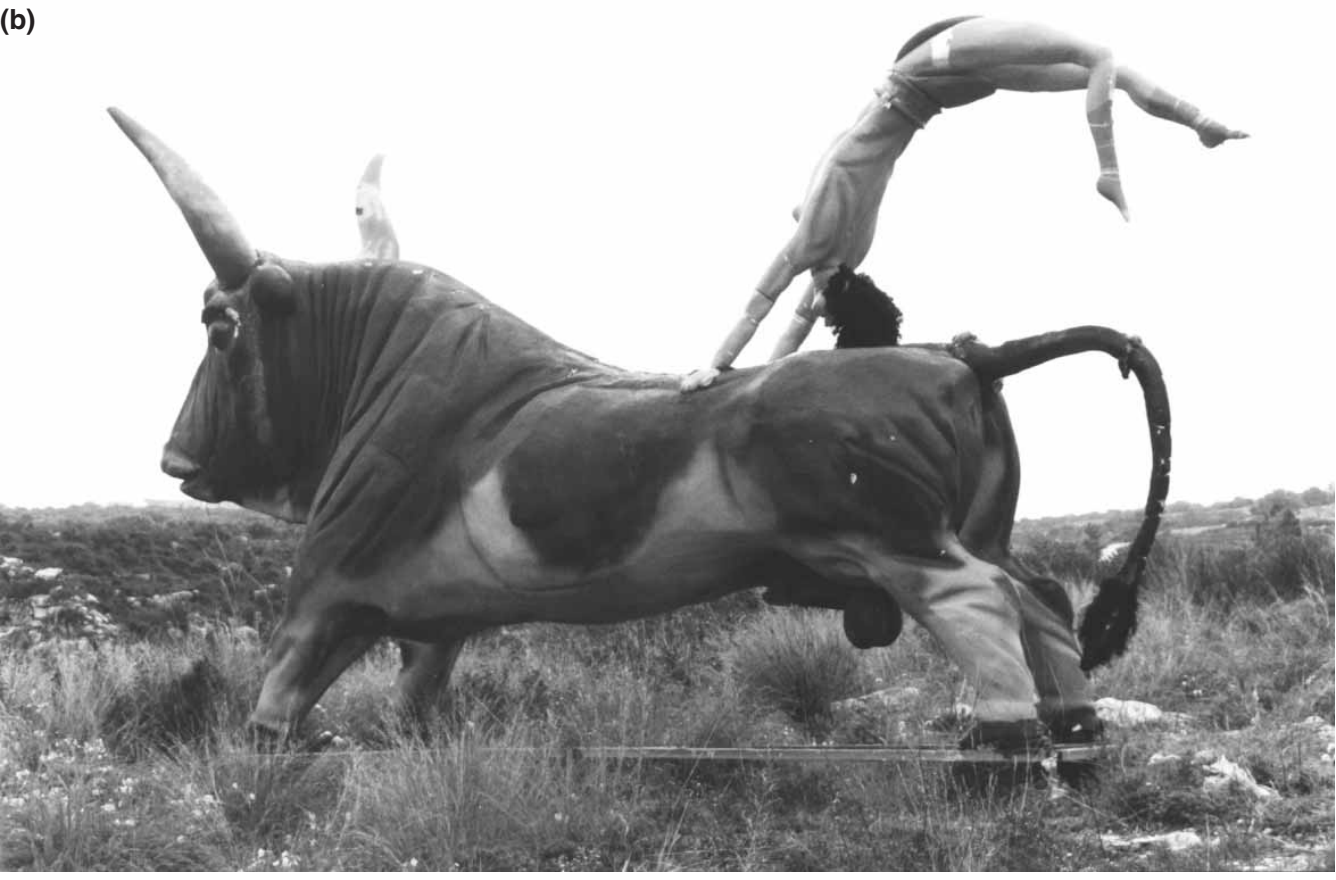

Plates $1 a$ and $1 b$ Carnival float on display at the outskirts of Rethymno, Crete, around 1997 (photos: Anna Simandiraki). 


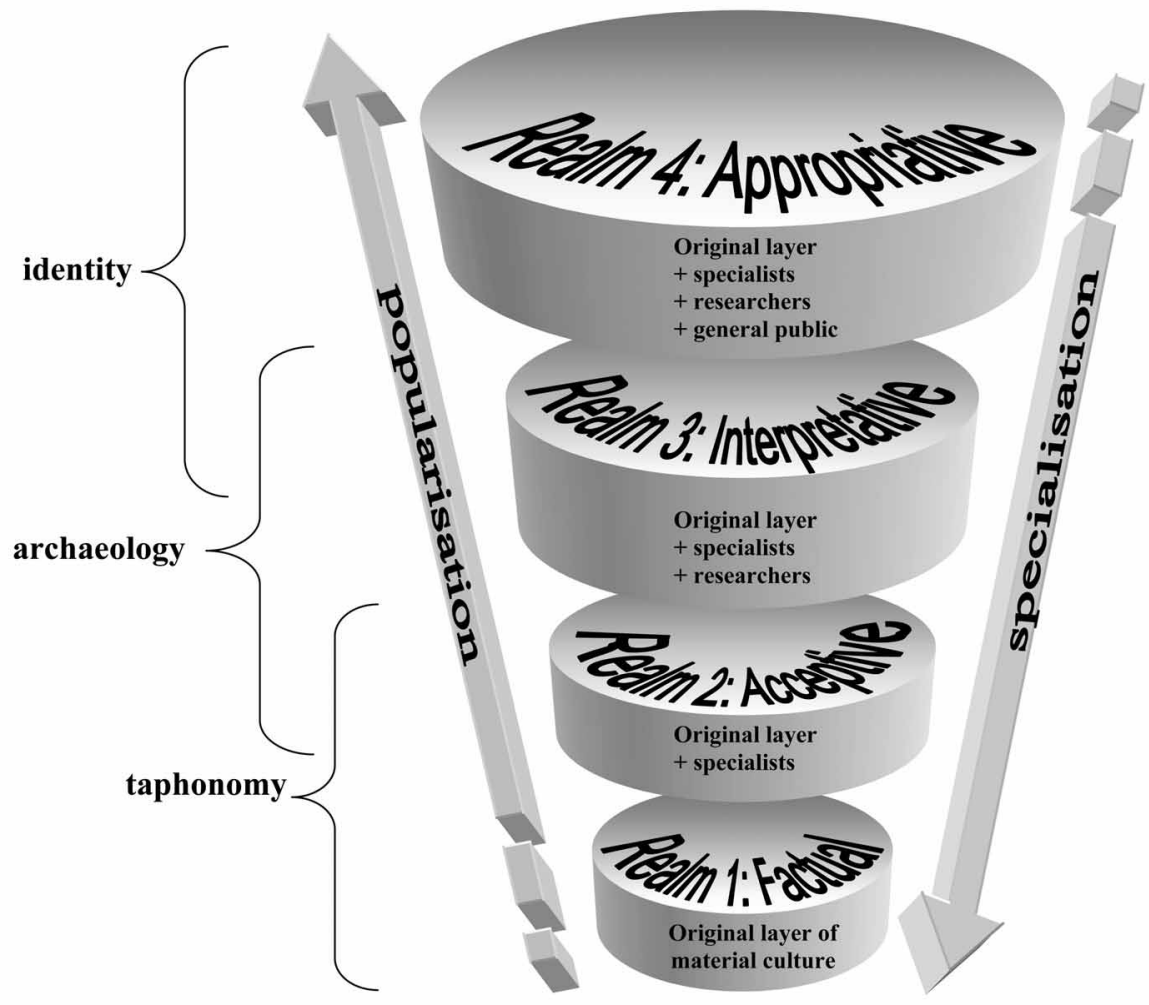

Figure 1 Stratigraphy of archaeological knowledge

Patrik 1985: esp. 29, 52; Hamilakis 1999: 69). The factual stratum, existing passively until now, is re-accepted into active reality and proceeds to occupy part of it, thereby joining a historicity different from its original one. The contents of this realm are the original layer of material culture + the specialists.

Realm 3: interpretative Here connotations, interpretations, consequences are attached to the factual material culture, as well as, frequently, to its acceptance into current reality. This stratum incorporates the original layer of material culture + the specialists + the researchers (the latter two can coincide: cf. Bintliff 1984: 34; Vestergaard 1987: 63; Hamilakis 1999). This paper is self-confessedly a Realm 2/3-based work commenting on a Realm 3/4 situation (with occasional references to Realm 1).

Realm 4: appropriative This is the realm where knowledge, sieved through and added to by processes of the previous realms, is appropriated by the current milieu (cf. Phillips 1998: 229). For (Minoan) archaeology, this means its deployment and employment within the current socio-political, national, intellectual and popular framework known as the public domain.

Interactions Several interactions can be distinguished. First, each realm is wider than the previous one. The more agents are introduced, the wider the interaction becomes, the wider the diffusion. Starting with the factual data, specialists (here: archaeologists) provide 
their own input, simply by discovering and, of course, interpreting. Realms 2 and 3 can be seen as very closely connected, as it is a fundamental human tendency to categorize and interpret data almost immediately after having acquired it (or, indeed, to search for raw data with those models already in mind). Archaeologists writing educational textbooks can be seen as an interaction of Realms $2+3+4$ (cf. Hamilakis 2003: 41).

Second, interactions also occur within realms. In Realm 3, the factual data are advocated by the specialists and debated by the researchers; the specialists streamline the factual data and collaborate with the researchers; researchers draw on extra experience to interpret the factual data, and liaise with the specialists to verify the record and distinguish patterns.

Third, there are overarching interactions. The trajectory from bottom to top is 'popularization'. The term is not derogatory; it just describes the diffusion of knowledge, from its factual state towards its appropriation by the mainstream. As mentioned above, the wider the realm becomes, themore data are attached to the originalcognitivecore. The outcome is a form of knowledge that, although containing some original evidence (which usually appeals more to the specialist), is enriched (and frequently distorted) by other heterogeneous but popular aspects of the mainstream. This is of paramount importance in understanding the Minoan civilization in primary education: one of the interactions at play is the selective representation of the past to conform to popularstereotypes and sanitize history (e.g. there does not seem to be any mention of Minoan sacrifice theories (cf. Hamilakis 2003: 48)).

The trajectory from top to bottom is 'specialization' and can be taken as the opposite of 'popularization'. Stripping of redundant, inaccurate, heterogeneous, prejudiced or any other input provides access to the lower, narrower realms. A child's initiation into the Minoan civilization occurs mostly in Realm 4 (sometimes in Realm 3), the outcome of some popularization process, whereas a (university) student's initiation heads the other way, 'unlearning' the mainstream and therefore choosing to join a different (more limited) audience, but with a wider set of data than that surviving in Realm 4.

Finally, Realms 1 and 2 seem to pertain to taphonomy (the term is used here to define a state of being and not the discipline): they seem to favour a material dimension. Realms 2 and 3 seem affiliated with archaeology (to the extent that that is a fusion of matter, time, space and interpretation), while identity construction is most prominent in Realms 3 and 4. Here the teaching of (Minoan) archaeology becomes a rite of passage, facilitating national consolidation and cultural assimilation. Of course, apart from the cognitive spheres, interactions also take place in temporal parameters. It is interesting, and probably not unrelated, that the Melina Programmes were launched at the wake of the national(istic) debates (the Macedonian problem, political tension with FYROM) and curriculum redesigning of the early 1990s. The advantages the archaeologist undoubtedly has are knowing all the realms, having been subjected to both popularization and specialization (in that order), and choosing to engage in or disengage from those procedures. I will return to a more in-depth discussion of the complexities of this construct in the near future (Simandiraki in preparation b).

\section{Minoan narrative: a palimpsest}

As can be seen in almost every book about the Minoan civilization for the primary school age cohort, there exists an inescapable fusion between fact and myth. King Minos is, for 
example, described in Very Old Times as a historical persona who lived in the palaces visible (as reconstructed ruins) today. This connection between fact and fiction is sustained in the book by the inclusion of excerpts from ancient historians, modern writers and poets (cf. Hamilakis 2003: 45, 48). A characteristic example is on p. 54, where an excerpt from Kazantzakis's In the Palaces of Knossos (80-1), used without a reference, implies authoritative and objective knowledge. Chapters 16 and 17, 'Daedalos and Ikaros' and 'A monster in the dark' respectively, consist almost entirely of mythology. Chapter 19, on the other hand, refers to the archaeological excavations and popularizes Sir Arthur Evans by including his caricature. This approach represents a narrativistic palimpsest in Realm 4 (Appropriative), whose layers are at least:

1. the archaeological record

2. the archaeologist

3. the ancient Greek perception of the Minoan past

4. the modern adaptation of the archaeological record

5. the modern adaptation of the ancient Greek perception of the Minoan past.

Concern and criticism about this approach of conglomerating the two narratives (factual and imaginary) should be voiced. In an educational textbook purporting to teach history, it is a paradox (to say the least) to employ fiction as historicity and not only to neglect to distinguish the two topoi, but also to make an effort to position them both in the sphere of reality. As mentioned above, the advantage that literature has when employing the same device is its self-confessed escapism and lack of authority.

\section{Memory and corporeality}

Cultural memory is initially transferred, produced and evoked here through verbal, textual and conceptual means. The, most frequently, fairytale-like exposure helps pupils of this age acquaint themselves with another reality, which, however, slips into their own. In this sense, although Very Old Times keeps the pupil engaged with its many exercises, these are to a great extent static: they tend to be text- and classroom-based, potentially limiting the experience physically and sometimes cognitively.

The Melina Programmes are significantly different. Interaction and multi-dimensionality are major advantages here. The pupil has a chance to use the classroom experience as a springboard into the physical and interactive dimensions of the past. Experiential learning thus proves far more productive and flexible: not only does the pupil's kinaesthetic reconstruction of the past provide stimulus and insight, it also gives the facilitator (teacher/archaeologist/guide) a palette of opportunities for exercises pertaining to other subjects, such as crafts, mathematics, physical education. It can, of course, be argued that, by imprinting in the affective educational domain (Krathwohl et al. 1964; Gagné 1985: 223) possible cultural/historical/(potentially) nationalistic stereotypes through directed corporeality, pupils become predisposed to or even possessive of this interpretation of the past (as they simultaneously gain ownership of their learning). However, one could also argue that the degree of critical adaptation of the past through these methods may outweigh the disadvantage. 
Educationally speaking, this more holistic approach to history/archaeology education does what, according to the myth, Daedalos did for statues, it animates it: a previously passive chore changes into pupils' ownership of their learning (ironically, it brings the archaeological experience closer to Hamilakis's 'sensory stratigraphy' (2002b: 127)). It shifts the pupil community from a large to a small power distance society (Hofstede 1991), where the gap between authoritative facilitator and passive receptor is bridged, and from a strong to a weak uncertainty avoidance society, where knowledge is less static and more negotiated. The discrepancy in Greek education as a result is that, because such approaches do not span all school years yet (with few exceptions (cf. Simoni and Papagiannopoulos 2001), pupils are forced back into the antiquated text-based instruction during gymnasium and lyceum.

\section{Joining the dots: the use of symbols}

Symbols are of great importance in the construction of a holistically represented past and the forging of a national identity (cf. Hamilakis and Yalouri 1996). They punctuate time, space, mindscapes of cultural (re)construction and they serve as identifying beacons towards a structured 'reality' of the past. The Minotaur of the classical myth is placed in the same reality as the partridge of the Partridge Fresco, the Minoans, even Sir Arthur Evans himself, all of which interact with the modern pupil (Angeletti 2000: 26-7, the excuse being that they are all interacting in the pupil's dream). Underlying symbols emerge here: the archaeologist as a digger, sometimes as a communicator of the past and its people (cf. Hamilakis 1999: 63, referring to Andronikos; also see Evans as a caricature in Very Old Times: 72; Angeletti 2000); ancient ruins equated with modern-day habitats; objects as tokens of a particular culture; tokens as life-aspect indicators; objects as conveyors of messages. All these selected elements of Realm 2 in Realm 4 outline a codified archaeological landscape and fill in the gaps (cf. Gagné 1985: 74; Hofstede 1991: 7-9). The Melina Programmes can be argued to continue the edification of antiquity, but they do this more subtly than museum visits or the theatrical plays of the Lykeio ton Ellinidon, while at the same time promoting a more dialectic, critical examination of the past.

\section{Conclusion}

While Hamilakis (2003: 56ff.) views books as weapons and cultural commodities, it is argued here that they can also be viewed as stratigraphic 'assemblages' created in the Appropriative Realm. The Minoan civilization in Greek primary education may be inadvertently intertwined with its classical depictions and utilized to support the notion of a historical continuum; it is also, however, an indicator of how knowledge, society and power are dynamic actors of the same interactive system.

\section{Acknowledgements}

I should like to express my warm thanks to Thomas Dowson for giving me the opportunity to contribute to this issue of World Archaeology, and for his encouragement and comments on a draft of this paper. Mrs Z. Simandiraki, Mrs M. Drakaki, Mr A. 
Papadakis and Ms L. Krommydaki have been of invaluable help concerning provision of information, textual material and encouragement. This paper would not have been possible without them and I am indebted to them for their co-operation and patience. Finally, I thank Dr M. Zeimbekis for her comments and constructive discussion on a draft of this paper.

\section{International Baccalaureate Research Unit, Department of Education, University of Bath, Bath, BA2 7AY, UK}

\section{Note}

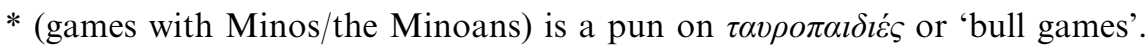

\section{References}

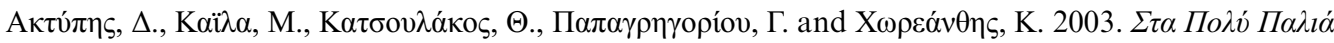

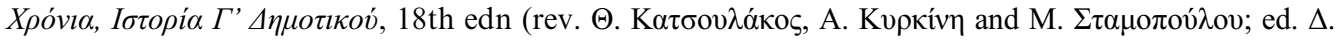

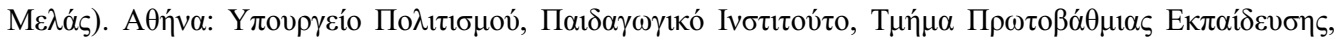

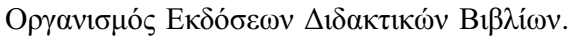

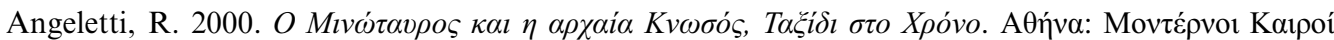
A.E.E.

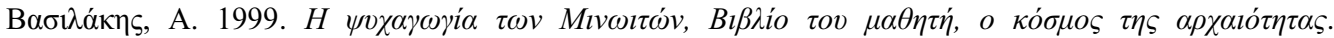

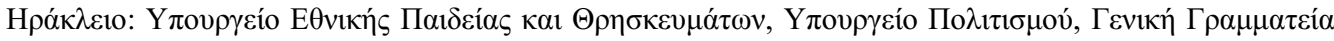

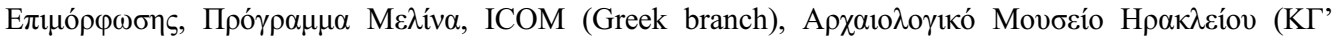
ЕПКА)

Bintliff, J. L. 1984. Structuralism and myth in Minoan studies. Antiquity, 58: 33-8.

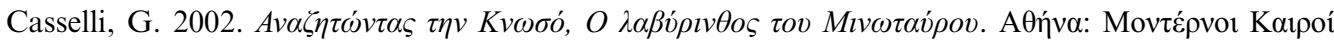
A.E.E.

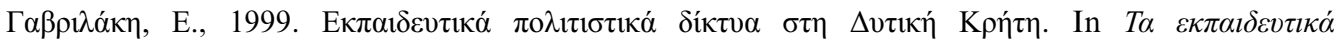

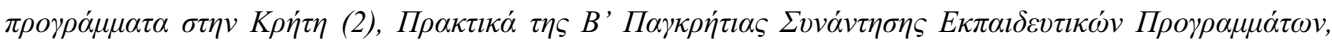

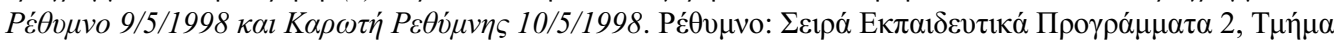

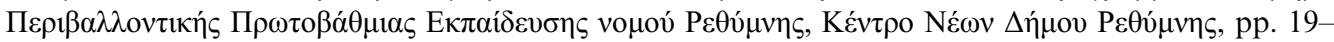
22.

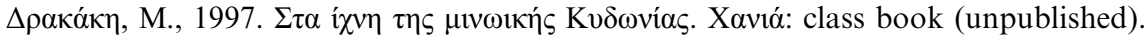

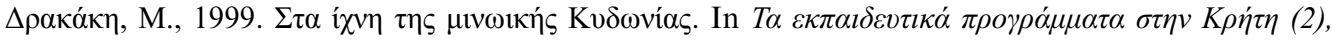

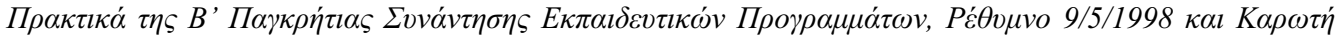

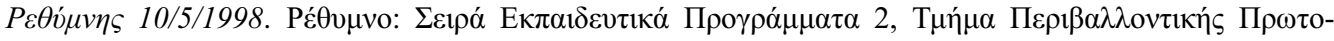

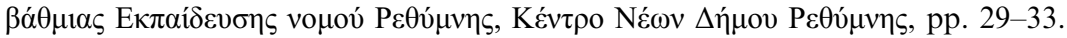

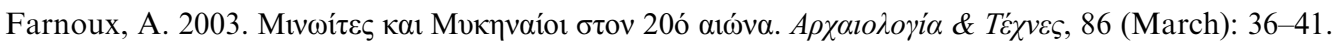

Gagné, R. M. 1985. The Conditions of Learning and Theory of Instruction. New York and London: Holt, Rinehart \& Winston.

Hamilakis, Y. 1999. La trahison des archéologues? Archaeological practice as intellectual activity in postmodernity. JMA, 12(1): 60-79.

Hamilakis, Y. 2002a. What future for the 'Minoan' past? Re-thinking Minoan archaeology. In Labyrinth Revisited: Rethinking 'Minoan' Archaeology (ed. Y. Hamilakis). Oxford: Oxbow Books, pp. 2-28. 
Hamilakis, Y. 2002b. The past as oral history: towards an archaeology of the senses. In Thinking through the Body: Archaeologies of Corporeality (eds Y. Hamilakis, M. Pluciennik and S. Tarlow). New York: Kluwer Academic/Plenum, pp. 121-36.

Hamilakis, Y. 2003. 'Learn history!' Antiquity, national narrative, and history in Greek educational textbooks. In The Usable Past: Greek Metahistories (eds K. S. Brown and Y. Hamilakis). Lanham, MD: Rowman \& Littlefield.

Hamilakis, Y. and Yalouri, E. 1996. Antiquities as symbolic capital in modern Greek society. Antiquity, 70: 117-29.

Hofstede, G. 1991. Cultures and Organizations. London: HarperCollins.

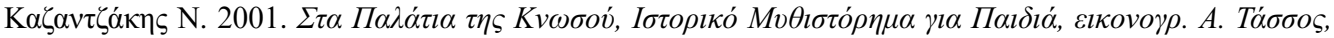
$\varepsilon \kappa \delta . K \alpha \zeta \alpha v \tau \zeta \dot{\alpha} \kappa \eta, A \theta \dot{\eta} v \alpha$.

Krathwohl, D. R., Bloom, B. S. and Masia, B. B. 1964. Taxonomy of Educational Objectives: The Classification of Educational Goals, Handbook II: Affective Domain. London: Longman.

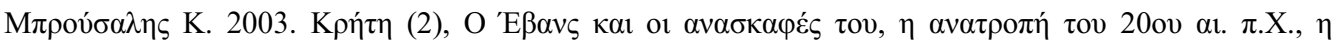

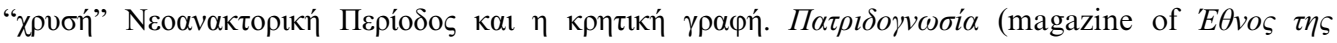
Kvрıккं́s), Sunday, 16/02/2003.

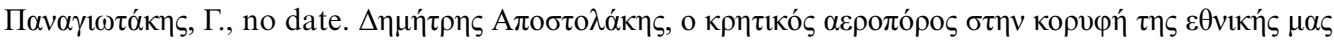

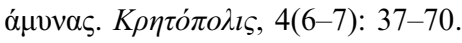

Patrik, L. E. 1985. Is there an archaeological record? Advances in Archaeological Method and Theory, 8: 27-62.

Phillips, R. 1998. Contesting the past, constructing the future: history, identity and politics in schools. In History and Heritage: Consuming the Past in Contemporary Culture: Papers Presented at the Conference Consuming the Past, University of York, 22 November - 1 December 1996 (eds J. Arnold, K. Davies and S. Ditchfield). Shaftesbury: Donhead, pp. 223-35.

Simandiraki, A. in preparation a. The branding of Minoan archaeology.

Simandiraki, A. in preparation b. Archaeology and the public: personal materiality as cultural artifact.

Simoni, H. and Papagiannopoulos, K. 2001. Can schoolchildren digitise their history? In Computing Archaeology for Understanding the Past, CAA 2000, Computer Applications and Quantitative Methods in Archaeology, Proceedings of the 28th Conference, Ljubljana, April 2000 (eds Z. Stančič and T. Veljanovski). Oxford: BAR International Series 931, Archaeopress, pp. 363-8.

Stewart, M. 1962. The Moon Spinners. London: Hodder \& Stoughton.

Vestergaard, E. 1987. The perpetual reconstruction of the past. In Archaeology as Long-Term History (ed. I. Hodder). Cambridge: New Directions in Archaeology, Cambridge University Press.

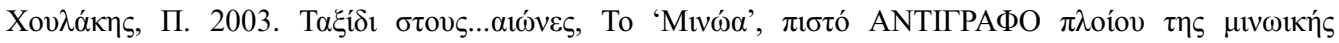

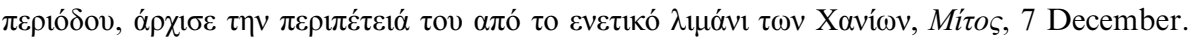

Anna Simandiraki completed her first degree (BA) in archaeology and history of art at the University of Crete, Rethymno, Greece (1997). She subsequently obtained an MA in Mediterranean archaeology (1998) and a PhD in Minoan archaeology (2002) from the University of Bristol, UK. Her research interests include Aegean Bronze Age ceramics, quantitative methods, religion, ethnoarchaeology, modern interpretations and adaptations of antiquity, educational theory. She has worked at the School of Conservation Sciences, Bournemouth University, and is currently working at the International Baccalaureate Research Unit, Department of Education, University of Bath. 
Copyright of World Archaeology is the property of Routledge, Ltd. and its content may not be copied or emailed to multiple sites or posted to a listserv without the copyright holder's express written permission. However, users may print, download, or email articles for individual use. 